\title{
ESTUDO DO CONTO OS CAÇADORES DE CAPIBARAS, DE AUGUSTO ROA BASTOS
}

\author{
Amanda Dorr ${ }^{1}$ \\ Eunice Piazza Gai ${ }^{2}$
}

Resumo: $O$ presente trabalho visa estudar o conto Os caçadores de Capibaras, de Augusto Roa Bastos. Para desenvolver o estudo, realiza-se um apanhado da vida e da obra do autor evidenciando sua importância na literatura latino americana. O conto inicia quando Margaret, protagonista, presencia o festival de San Juan, comemoração feita pelos carpincheros, povos nativos habitantes da região do Tebicuary Guairá. Margaret fica fascinada com os caçadores desde a primeira vez em que ela os vê, o desfecho da história se dá quando Margaret foge com eles. A literatura é capaz de transformar os seres humanos em pessoas melhores por permitir a fantasia, o imaginário e encantamento. Pode-se estudar esse conto dessa forma não pelos caçadores de capibaras serem um livro, eles são reais, as histórias que ela conhece acerca deles são contadas por pessoas. E essas histórias são capazes de fazê-la imaginar um mundo além daquele que ela vive.

Palavras-chave: Roa Bastos; Encantamento; Imaginação.

\begin{abstract}
This paper investigates the tale The hunters of Capibaras, written by Augusto Roa Bastos. To develop the study, it was important an overview of the life and work of this author, demonstrating his importance in Latin American literature. The tale begins when Margaret, protagonist, witnesses the festival of San Juan, made by carpincheros, people native of the Tebicuary Guaira region. Margaret became fascinated with the hunters since the first time she saw them, and the outcome of the story is when Margaret flees with them. Literature is able to transform human beings into better people for allowing fantasy, imagination and enchantment. People can study this tale this way not for the reason that The hunters of Capibaras is a book, but bacause they are real, the stories she knows about them are told by real people. And these stories are able to make her imagine a world beyond that one which she lives.
\end{abstract}

Keywords: Roa Bastos; Enchantment; Imagination.

\footnotetext{
${ }^{1}$ Aluna do Mestrado em Letras Leitura e Cognição - UNISC, Universidade de Santa Cruz do Sul. Bolsista FAPERGS - RS, Brasil. E-mail: amandadorr1@ gmail.com

${ }^{2}$ Professora Metrado em Letras Leitura e Cognição - UNISC, Universidade de Santa Cruz do Sul. RS, Brasil.E-mail: piazza@unisc.br
} 
Augusto Roa Bastos nasceu em Assunção, Paraguai, em 1917. Aos dois anos foi viver em um engenho de açúcar em Iturbe, Guairá, onde a mãe lia para ele, em espanhol, trechos da Bíblia e de obras de Shakespeare, e the contava lendas e mitos indígenas. Aos quinze anos, Roa Bastos abandonou os estudos para alistar-se, como voluntário, na Guerra do Chaco, atuou na enfermaria, mas seu desejo era estar na frente armada. Foi exilado por mais de três vezes, sendo acolhido por países como Argentina, França, e Espanha. Nesses países, trabalhou como correspondente internacional para alguns jornais, lecionou em algumas universidades e iniciou sua trajetória como escritor.

Em 1945, trabalhou como correspondente do El País, em Assunção, cobrindo o fim da II Guerra Mundial. Em 1947, um governo militar repressor obrigou-o a exilar-se em Buenos Aires, onde trabalho como jornalista, roteirista de cinema, carteiro, dramaturgo e professor, e de onde sairia, em 1976, instado por outra ditadura, para um longo exílio na França. Convidado pela Universidade de Toulouse- Le Mirail, passou a dar aulas de Literatura Hispanoamericana e de Língua e Cultura Guarani. Ao voltar para o Paraguai, em 1982, teve cassada sua cidadania paraguaia. Obteve, no ano seguinte, a cidadania espanhola. Com o fim da ditadura de Stroessne, em 1989, passou a visitar seu país, retornando mais tarde a viver em Assunção. Além de escrever romances, contos, poemas e ensaios, Roa Bastos compôs músicas, peças teatrais, roteiros cinematográficos, entre outros.

Luis Alberto Sánchez (1976) trata do escritor Roa Bastos em um dos seus capítulos. Segundo ele, se houvesse um modelo de escritor Roa atingiria todos os requisitos ideias previstos por esse protótipo. Além disso, ele pertence a um país misterioso, que junto com a Bolívia formam uma das incógnitas sulamericanas.

Ainda para Sánchez (1976), o Paraguai sempre foi um território impar localizado no centro da América de colonização espanhola. Os jesuítas ali estabeleceram suas missões, o que faz com que seja chamado de selva missioneira até hoje, como uma recordação daquela estrutura social e política do século XVI. "La compañía de Jesús instaló en Misiones un régimen de 
gobierno severo. Ejercían el poder los propios jesuitas, em forma colectiva" ( $p$. 142). Assim, os jesuitas se ocupavam não só com as tarefas de paz como também com as de guerra. Ao serem expulsos da Espanha e de suas colônias, os jesuitas em 1967, tiveram que deixar o território das missões que tornou-se com isso uma terra sem governo: "[...] se produjo eso que los sociólogos de hogaño, más linguistas que sociólogos, llaman 'un vacío de poder' " (1976, p. 143).

O ditador, Francia, exerceu a autoridade do país de 1811 até 1840, durante esses anos manteve o Paraguai. Criou uma igreja Católica, e proibiu o matrimônio entre brancos para assim formar a mestiçagem. O livro Yo, el supremo, de Augusto Roa Bastos, é intitulado assim porque o Doutor Francia era também chamado por "el Supremo". Tratando-se de um personagem e de uma época tão confusos, sentiu problemas ao adequar o estilo ao assunto, a obra se tornou de difícil leitura. A obra destacou-se entre outras que tratam de tiranos tropicais pela fidelidade de suas informações e pela maneira que o autor trata da realidade. Com essa narrativa, Roa confirma seu prestigio literário recriando personagens de diversas lendas e mitos de seu país.

Este artigo estuda o conto Os caçadores de Capibaras, que se inicia quando Margaret personagem principal presencia os caçadores de Capibaras na noite de São João. As fogueiras brotavam da própria água, e era através delas que se fazia possível enxergar os caçadores de capibaras. Eles estavam em canoas, cada uma delas, tinha os mesmo tripulantes, dois homens remando com varas compridas e uma mulher sentada no bojo, com uma pequena panela. Todas as mulheres pareciam velhas, enrugadas e fracas. Já os homens, tinham aparência de duros e fortes. Pareciam até estarem andando sozinhos pois eram os únicos que se mexiam. Fascinada, Maragaret pergunta com voz rouca:

[...]-Como é que as acendem sobre as águas-continuou a exigir Margaret."...

E assim ela continuou a questionar seu pai, com muita curiosidade e um forte encantamento pelos costumes daqueles que viviam na água. Seu pai também lhe falou que os trabalhadores da fabrica admiravam muito os caçadores de capibaras por eles serem livres no rio enquanto eles são como escravos na fábrica. 
Desde então a fantasia de Margaret ficou totalmente ocupada com os caçadores de capibaras. Tinham nascido do fogo diante dos seus olhos. As fogueiras da água tinham-nos trazido. E tinham- se perdido no meio da noite como fantasmas de cobre, como subtis personagens de fumo.

A explicação do pai não a satisfez de todo, salvo talvez num ponto: os homens do rio eram seres invejáveis. Para ela, eram, além disso, seres formosos, adoráveis (BASTOS, 1984, p. 16).

Algum tempo depois seu pai cumpriu a promessa e levou-a a conhecer São João de Borja, lugar onde passa o rio entre a povoação. Margaret observou tudo com os olhos curiosos, mas duvidou que ali nascessem as fogueiras que traziam os caçadores de capibaras:

Torturou sua imaginação e inventou uma teoria. Deu-lhes um nome mais de acordou com a sua misteriosa origem. ChamouIhes homens da lua. Estava absolutamente convencida de que eles provinham do pálido planeta da noite devido à sua cor, ao seu silêncio, ao seu estranho destino (BASTOS, 1984, p. 16).

Margaret e seus pais, Ilse e Eugen, não fazia muito tempo que tinham chegado ao engenho de açúcar de Tebikuary do Guaira. Vieram diretamente da Alemanha, um tempo depois de encerrada a Primeira Guerra Mundial. O lugar lhes parecia muito bom já que estavam vindo das ruínas, da fome e do horror. Só depois também foram descobrir o horror que era viver ali também. Estavam muito sofridos das tristezas que viveram. Primeiramente viveram em um barracão de latas velhas, nos fundos da fábrica. Faziam tudo ali, entre as urtigas e ferrugens. Eugen era um excelente mecânico torneiro, de modo que, depois, puseram-na à frente da oficina de reparações. A administração forneceu-lhe a casa branca com teto de zinco, ficava no solitário recanto do rio.

Nessa casa onde passaram a viver fora assassinado o primeiro testa-deferro de Simón Bonaví, dono do engenho. Eugen foi prevenido por um dos trabalhadores que Ihe dizia que o morto costumava assombrar quem por ali estava. Ele não era supersticioso e por isso não se importou com o recado, já Margaret ao cair da noite, se refugiava nos braços da mãe. Ela estava sempre triste, até que viu os caçadores de capibaras entre as fogueiras, na noite de São João. Subiram em um morro e assim conseguiram ver bem o rio. Ela ficou 
extremamente feliz com tudo que via e assim deixou seus pais tranquilos e felizes por verem que estava bem.

Margaret foi descobrindo a vida naquele novo lugar e começou a gostar de tudo que a cercava. Nas noites de verão, depois de jantarem, a família saía para se sentarem no barranco. Ficavam ali a apanhar fresco até que os mosquitos se tornassem insuportáveis. Ilse cantava canções da sua aldeia, Eugen cansado do trabalho, ficava olhando para cima recordando o seu antigo e perdido ofício de marinheiro. Mas não deixava de pensar nos escravos do engenho, algo que lhe preocupava muito. Já Margaret com sua cabecinha prateada, ao contrário de seu pai, pensava nos homens livres do rio, seus fabulosos Homens da Lua. E assim, todas as noites esperava vê-los:

Os caçadores de capibaras apareceram mais duas ou três vezes ao longo desse ano. À luz da lua, mais do que ao fugor das fogueiras, adiquiriam a sua verdadeira substânciamitológica no coração de Margaret ( BASTOS, 1984, p. 20).

Em uma noite, eles desembarcaram na areia, acenderam pequenas fogueiras, comeram e em seguida, dançaram algo estranho e rítmico, ao som de algo muito parecido com o arco. Uma de suas pontas penetrava na metade de uma cabeça, forrada com couro de capibara esticado. O tocador passava a corda do arco pelos dentes e arrancava-Ihe um zumbido surdo e profundo. "Tum-tu-tum... Tam-ta-tam... Tu-tum... Ta-tam... Tu-tummmm..." ( BASTOS, 1984, p. 21). Margaret estava com sua respiração exatamente do compaço da música, sentia-se misteriosamente ligada aqueles barulhos embutidos nos barrancos. A música parou, os barcos puseram-se em movimento e foram sobre o mar até que aos poucos nada mais era visto.

Cada vez mais impaciente, ela estava sempre a espera deles, sabia sempre quando iriam aparecer e ficava muito agitada até avistar o primeiro cachiveo aparecer na distante curva, no profundo leito do rio:

-Vêm aí! - a vozinha de Margaret ficava rouca de emoção.

A cantoria fanhosa ou o silêncio de llse interrompiam-se. Eugen intrometia-se, assustado.

-Como sabes, Gretchen? 
-Não sei. Sinto que vêm. São os Homens da Lua...(BASTOS, 1984, p. 21).

Ela nunca errava, em seguida eles surgiam e seu coração palpitava com muita força. Seus olhos ficavam vagando pelo rio até que o último deles ainda pudesse ser visto. Nessas noites, ela desejava ficar no barranco até o amanhecer, porque ela acreditava que a qualquer momento ele poderiam voltar a subir a corrente. Sempre lamentava-se que não queria entrar, nãos gostava da casa branca e por isso implorava para que seus pais a deixa-se ficar. Uma vezes foi necessário que levassem ela arrastada, teve um ataque de nervos que a fez chorar a noite toda. Seus pais estavam muito preocupados por acharem que o espetáculo dos caçadores de capibaras estivesse deixando-a doente, assim, decidiram não saírem mais para assisitir.

Durante alguns meses Margaret não conseguiu ver os Homens da Lua. Uma noite, ela já estava deitada e ouviu eles passarem na garganta do rio. Chorou em silêncio para que seus pais não pudessem ouvi-la. Fechou seus olhos e a visão lhe vinha a cabeça, era capaz de imaginar-se junto a viagem como se eles estivessem a sua frente. Foi como se ela de repente ficasse tranquila, foi acalmando-se cada vez mais. No dia seguinte já estava triste novamente, pois a pior coisa que poderia lhe acontecer era ser proibida de ver os caçadores. Com o tempo ela passou a se sentir melhor e a relação com sua família também melhorou.

Novamente chegou a noite de São João, noite das fogueiras sobre a água. Margaret, Ilse e Eugen estavam jantando quando ouviram as primeiras ilhotas iluminadas descerem pelo rio. Olharam-se pensativos, até que o senhor Eugen sorriu e disse: "-Sim, Gretchen. Esta noite iremos ao barranco ver passar as fogueiras" ( BASTOS, 1984, p. 23). Nesse momento ouviram o uivo de um animal ou de um homem. Ao ouvirem novamente sairam correndo para o barranco. Com a luz das fogueiras foi possível perceber que era um dos caçadores de capibaras lutando com um animal que dava saltos como uma bola de prata peluda. Eugen, horrorizado, avisou que aquele animal era um 
tigre da água. Os caçadores já estavam saindo dos barcos para socorrer 0 amigo, mas tudo ocorreu muito rápido e já não havia mais tempo.

Ilse estava com o rosto coberto por suas mãos, estava espantada. Eugen estava pálido e rígido, comprimindo a barriga. Só Margaret estava com o semblante de quem contemplou a luta com expressão impassível e ausente. Só o ritmo de sua respiração estava mais agitado. Os caçadores de capibaras pareciam não saber o que fazer. Por fim, carregaram o ferido e puseram-no em um cachiveo. Todos atravessaram o rio e subiram pelo barranco. Cada vez mais próximos, Margaret via os Homens da Lua. Eles eram meio índios, com cabelos bem pretos, com olhos pequenos e em cada um deles havia uma pequena fogueira:

[...] Vinham a subir, as caras angulosas com pomos de pedra verde, os torsos de cobre e sarmentosos, as mãos imensas, os pés córneos e chatos. No meio vinha o morto, que já estava cor de terra. Atrás subiam as mulheres andrajosas, fracas e mamudas. Subiam, trepavam, rastejavam até acima como sombras agarradas ao resplandecente barranco. Com eles vinham as chispas das fogueiras, as vozes guturais, o canto de iguano ferido, as vozes guturais, o canto de iguano ferido de algma mulher, vinham os latidos lançados pelos cães, vinha um odor de plantas aquáticas, de pescado apodrecido, de catinga de capibara, de suor... ( BASTOS, 1984, p. 25)

Ilse chamou depressa a filha e arrastou-a até a casa, enquanto Eugen trazia o candeeiro e arrumava no corredor da casa uma cama de couro, onde pediu que colocassem o ferido. Em seguida correu para a enfermaria para ver se ainda seria possível prestar socorro. Enquanto isso Margaret fica prestando atenção naquele caçador deitado no corredor de sua casa, com o sangue gotejando no chão. Observa como seus pés são grandes e pensa que esses pés nunca mais poderão andar sobre as águas e fica muito triste. Sua mão se estende até a grande mão escura do mais velho de todos os caçadores. Todos vão saindo da sala, ficando somente o morto. Margaret já não estava mais ali. Sua mãe sai da cozinha gritando por seu nome, desce o barranco e vê que os cachiveos já dobram a curva, no meio das fogueiras. No entanto, Ilse avista os 
cabelos de leite de Margaret antes de desaparecerem completamente. Ela então diz "Gretchen..., mein herzschen...!" ( BASTOS, 1984, p. 26).

Este trabalho é decorrente de uma pesquisa dedicada às narrativas contemporâneas. Buscando estabelecer as principais tendências dassas narrativas, no que diz respeito à perspectiva estética mais ampla, considerando os principais temas e as problemáticas abordadas. Vale-se da hermenêutica para elaborar a interpretação do conto selecionado.

Considera-se que os seres humanos vivem em um mundo cheio de inquietações e incertezas e estão sempre em busca de encontrar a si mesmos e procurar respostas para seus conflitos pessoais, culturais, entre outros.

Entende-se a leitura de narrativas como um auxílio na busca de um conhecimento interior, uma vez que a leitura, como uma ação interpretativa, permite também uma autointerpretação. Acredita-se que a ação de interpretar possibilita a ampliação dos conhecimentos sobre o ser humano e, também, sobre a forma de ver o mundo e a si mesmo.

De uma maneira filosófica, considera-se que certas ideias que eram mantidas como verdades absolutas passam pela consciência humana através da leitura e escuta de narrativas e se transformam. Assim, vai se formando a identidade a partir das histórias que se lê e das que são contadas; elas vão se modificando, ganhando um tom subjetivo, auxiliando a construir um sentido para a vida, para o mundo, a partir do conhecimento já existente.

Larrosa (2003) mostra que, através das narrações, vai-se constituindo o sujeito, pois o fato de narrar-se faz pensar, criar, imaginar e o mesmo acontece quando se ouve as narrações. Desse modo, ocorre a formação enquanto leitores e também como seres humanos.

Em uma história, assim como se pode perceber no conto de Roa Bastos, por meio das narrativas que Mergaret ouve, ela envolve-se na história e com a linguagem utilizada pela pessoa que conta. E, quando se entra com a subjetividade, interpretar o texto transforma a identidade com o conhecimento que se adquire durante a leitura. Assim, a história da vida dos indivíduos depende do conjunto de histórias que ele ouve, lê. 


\section{REFERÊNCIAS}

BASTOS, Augusto Roa [et al.]. O livro da Guerra Grande. Rio de Janeiro: Record, 2002. . O trovão entre as folhas. Lisboa: Edições 70, 1984.

D’ONÓFRIO, Salvatore. Teoria do texto. São Paulo: Editora Ática, 2006.

ECO, Umberto. Interpretação e superinterpretação. São Paulo: Martins Fontes, 2001.

GUIMARÃES, Acyr Vaz. A guerra do Paraguai: suas causas. Campo Grande: UCDB, 2001.

HESSEN, Johannes. Teoria do conhecimento. 2 ed. São Paulo: Martins Fontes, 2003.

LARROSA, Jorge. Pedagogia profana. Belo Horizonte: Autêntica, 2004.

Literatura e História na América Latina: Seminário Internacional.

Organizadores: Ligia Chiappini e Flávio Wolf de Aguiar. 2 ed. São Paulo:

EDUSP, 2001.

SÁNCHEZ, Luis Alberto. Escritores representativos de América. Madrid: Editorial Gredos, 1976.

SHAW, Donald L. Nueva narrativa hispanoamericana. Madrid: Cátedra, 2005.

VERSEN, Max von. História da Guerra do Paraguai. Belo Horizonte: Ed Itatiaia; São Paulo: Ed da Universidade de São Paulo, 1976. 